\title{
Survey of Tools and Techniques for Sentiment Analysis of Social Networking Data
}

\author{
Sangeeta Rani ${ }^{1}$, Nasib Singh Gill ${ }^{2}$, Preeti Gulia ${ }^{3}$ \\ Department of Computer Science and Applications \\ Maharishi Dayanand University, Rohtak, India
}

\begin{abstract}
Social media has rapidly expanded over a period of time and generated a huge repository of content. Sentiment analysis of this data has a vast scope in decision support and attracted many researchers to explore various possibilities for technique enhancement and accuracy improvement. Twitter is one of the social media platforms that are widely explored in the area of sentiment analysis. This paper presents a systematic survey related to Social Networking Sites Sentiment Analysis and mainly focus on Twitter sentiment analysis. The paper explores and identifies the techniques and tools used in a well-structured approach to find out the research gaps and identify future scope in this area of research. The techniques evolved over time to improve the efficiency of classification. Total 55 research papers are included in this survey. The result reflects that Twitter is the most explored social networking site for opinion mining. Naïve Bayes and SVM machine learning algorithms are implemented in maximum researches. As the latest advancements, Stack based ensemble, fuzzy based and neural network based classifiers are also implemented to enhance the efficiency of classification. WEKA, $R$ Studio, Python are mostly used tools by research scholars for implementation. The overall evolution of the research goes through various changes in terms of technologies, tools, social media platforms and data corpus targeted.
\end{abstract}

Keywords-Social networking sites sentiment analysis; twitter sentiment analysis; opinion mining; ensemble classifier; stack based ensemble

\section{INTRODUCTION}

The spread of information on social networking media like Facebook, Twitter, Instagram, Reddit, News forum etc. is comparatively faster than traditional social media platforms. Social media have become a rich resource of information for companies and research scholars that can be analyzed to get valuable information by using NLP (Natural Language Processing) and artificial intelligence techniques. The huge repository of information provided on social media platform is unprocessed and raw in nature, and over the time technologies are evolved to process the data and extract valuable information from that. This information can be analyzed and helpful in decision support and effective policy making in different areas related to business, politics, entertainment, medical and social uplifting.

Sentiment analysis of social media posts deals with finding out the opinion, sentiment or feelings related to these posts.
That can be mentioned at different levels of sentiments and mostly categorized as positive and negative. Several sentiment analyses and classification techniques like dictionary based, machine learning, ensemble based, neural network based, fuzzy based and hybrid are evolved over the period of time starting from the research in the area. Also, the targeted data size is increased and new tools are evolved for easy and effective evaluation of sentiment. Various research scholars have been doing research for more than a decade and research has gone through multiple phases with enhancement of technology and efficiency of outcomes.

Here in the present survey we have gone through a systematic literature survey and studied 55 finally selected research papers related to the area from 2009 to 2021. These 55 papers are selected after keen observation and following the criteria of inclusion and exclusion. We focus on Twitter sentiment analysis and provide the existing techniques used and scope of enhancement. There is abundance of research literature present in the field; we aim to find the relevant literature with respect to novelty of research, their applications domain and effectiveness.

Section I of the present survey paper gives the introduction of sentiment analysis for social networking sites. The research strategy used in the survey is mentioned in Section II. Research questions on the basis of which the survey is designed are mentioned in Section III. Section IV gives the details of related literature included in the survey. Survey outcomes of all the 55 research papers included are mentioned in Section V. Overall survey is concluded in Section VI.

\section{RESEARCH STRATEGY DESIGN}

The survey related to 'Social networking sites sentiment analysis' was undertaken systematically by following the steps mentioned in Fig. 1. At the very first step, research questions are designed to give a proper direction to the survey. We continue by retrieving the related literature and then selecting the pertinent research papers from those that fulfill the requirement as per research questions. Finally, the findings and results as started by the author are analyzed and mentioned along with tools and technology used in the research. 


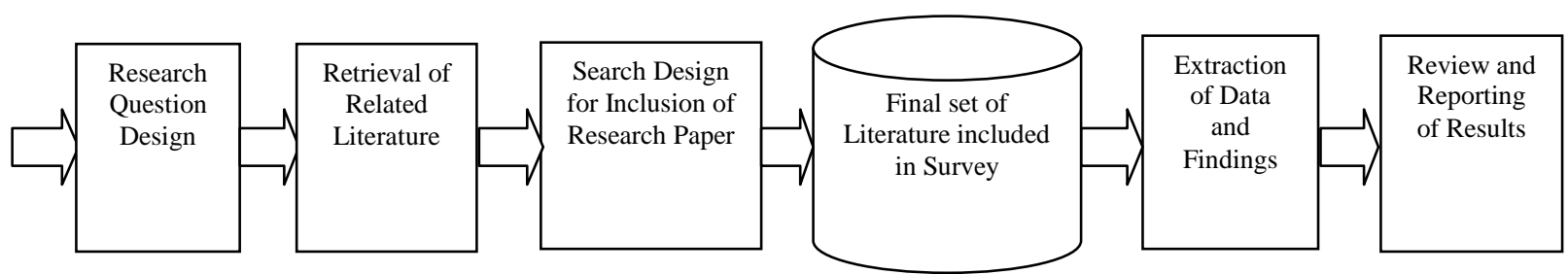

Fig. 1. Stepwise Strategy Design for Literature Review.

\section{RESEARCh QUESTION}

To design and conduct research, the following research questions (Q) are identified:

Q1: Which technique is used in the research?

Q2: Which framework, language or tools are used in research for implementation?

Q3: Which datasets are targeted in the research for implementation of mentioned models?

Q4: What are the main outcomes of the research literature?

\section{RELATED LitERATURE}

Various researches performed in the area from 2009 to 2021 are mentioned below. Table I gives the summarization and key findings of the survey. The results, technologies, findings and tool used in the research are also elaborated in the section below:

Matthew et al. [1] in their research, implemented Bagging, Boosting and Random subspace method by using KNN, C4.5, SVM, MLP, RBF, LR as base classifiers. WEKA tool is used in the implementation of different classifiers. An enhanced performance is obtained with maximum accuracy of $90 \%$ over other approaches. Ensemble-based classifier performed better in all cases, particularly for noisy data, to enhance the overall accuracy of classification.

Kumar et al. [2] presented an article about the evolution of online social networks. The article investigates the dynamics of social cognitive theory and social networking. The research involved a photo sharing application (Flickr) and Yahoo 360 social network for analysis and implementation. Three different segments of networks are identified viz. singletons, isolated communities and giant component networks and detailed description of the evolution and structure of the three segments are researched on. The investigation of economical behavior of online social media networks is analyzed and user activity impact on incentives is examined.

A. Agarwal et al. [3] proposed twitter sentiment analysis by using POS specific polarity features and explored tree kernels to prevent the need for tedious feature engineering. 11,875 manually labeled tweets publically available from commercial resources were used in implementation. The conjunction of new feature with the previously proposed features and tree kernels outperform the base line classifiers.

Bae Y. et al. [4] performed twitter sentiment analysis of twitter post related to famous personalities and news channels viz. Donald J. Trump, Barack Obama, Bill Gates, Ashton Kutcher, Lady Gaga, Larry King, Oprah Winfrey,
Britney Spears, TechCrunch, Mashable, BBC Breaking News, CNN Breaking News, Dalai Lama.

Lima et al. [5] in their research implemented Naïve Bayes algorithm for tweets sentiment classification as positive and negative on real time tweets downloaded by using Twitter4J Library. Tweets are classified on the basis of emoticons, sentiment based words or a hybrid of both. The results show an enhanced accuracy in case of hybrid approach.

F. Neri et al. [6] implemented sentiment analysis on Facebook posts related to news post related to Rai1 and La7 news programs. Facebook posts are analyzed using 'iSyn Semantic Center'. Bayesian method and K-Means algorithm are used as supervised and unsupervised classification techniques. The research shows the importance of Facebook for online marketing.

H. Kang et al. [7] proposed an enhanced Naïve Bayes classification algorithm for sentiment classification of review documents of restaurants. The 70000 review documents are obtained from restaurant sites including star information. The proposed model shows the enhancement of accuracy and precision.

M. Ghiassi et al. [8] developed a new lexicon specifically for Twitter opinion mining using n-gram feature vector and supervised learning method. The 3440 tweets are manually collected and labeled on 'Justin Bieber' twitter account and the model proposed in research is tested using these tweets. The results show the improvement in accuracy for the proposed model over SVM with an accuracy of $95.1 \%$.

Hassan et al. [9] implemented Bootstrap ensemble framework (BPEF). It works in two stages: expansion and contraction. In the expansion stage, large numbers of models are generated based on the dataset, features and classifier parameters. In contraction stage a subset of these models is selected by throwing redundant and less useful models. The experiment results show that BPEF gives a high value of recall as compared to other methods. SIMS module of BPEF extracted a model with higher performance.

E. Haddia et al. [10] show the role of preprocessing on sentiment analysis. Improvement is observed in the accuracies of TD-IDF matrix from 78.33 to 81.5, in Metric FF 76.33 to 83 and in FP matrix 82.33 to 83.

Patil et al. [11] in their research implemented SVM with and without feature extraction and show that SVM eliminated the need for feature selection due to the ability to generalize high dimension feature space.

Inoshika et al. [12] research on feature ranking and selection techniques for Twitter data opinion mining and 
suggested to remove unrelated words from feature space to reduce dimensionality that further reduces the sparseness of the feature set. The research also proposed a new feature selection technique on the basis of information theory named as Ratio Method.

Bac Le et al. [13] proposed a model based on NB and SVM. Information Gain, Bigram, Object-oriented extraction methods are used for feature ranking and selection to select more appropriate features. As per reported results, the proposed model is highly efficient with high accuracy for predicting feelings.

B. S. Dattu [14] implemented twitter sentient analysis by using SVM and Naive Bayes on real time tweets downloaded between the time periods 12 September 2010 to 24 January 2011 with the keywords 'NFL teams'. They pointed out in their research that SVM proved to be better than Naive Bayes algorithm for text classification and categorization. For unbalanced data, Naïve Bayes is more appropriate as there are fewer variations in results for unbalanced data.

O. Kolchyna et al. [15] implemented two techniques viz. Lexicon based and machine learning for sentiment classification of twitter messages. This research uses the sentiment score extracted from Lexicon classifier as an additional feature in the feature vector and the results shows the improvement in accuracy for imbalanced data set. The research show that incorporating sentiment lexicons with abbreviations, emoticons and social media slang enhances the efficiency of lexicon-based classifier. Feature generation and selection also play a vital role for the enhancement of classification accuracy. SemEval-2013 competition, task 2-B standard twitter data set is used and the outcome of the research shows that SVM and NB machine learning methods perform better. A combination of lexicon and machine learning method further enhance the accuracy by 7 percent.

Prusa et al. [16] worked on bagging and boosting-based ensemble classifiers. These two are the most widely used ensemble techniques in machine learning. In the research, both techniques are tested with the use of seven diverse base learners. All the ensemble classifiers build are compared with all the seven base learners to observe the performance enhancement. Total 21 learning algorithms are trained and finally tested on two different datasets, one large-sized automatically class labeled lesser quality dataset and other small-sized manually class labeled superior quality dataset. The research proved to be better and ensemble classifier enhanced the accuracy, regardless of the quality of the data set used.

K. L. Devi et al. [17] compared ensemble classifiers viz. Boosting and Bagging with the machine learning classifiers like NB, SVM and maximum entropy classifier. Feature selection is performed by using MI and Chi-square methods and is proved to be better than previously used methods. SemEval 2013, Task 9 data sets are used for implementation.

Y. Wan et al. [18] in their research, implemented majority voting-based ensemble classification model on various classification techniques including SVM, Random Forest, Naive Bayes, Bayesian Network and C4.5 Decision Tree by using 10 fold cross validation on a data set having 12864 tweets related to airline service Twitter dataset.

Prusa J. et al. [19] researched on 10 different feature selection methods and four classifiers viz. 5-NN, C4.5, LR, MLP. All classifiers by using all feature ranking and selection techniques are implemented on 10 different sized feature subsets up to maximum 200 features. The results of research show that filter-based feature selection, Chi-Squared (CS) improved classification performance for small-size feature sets. After comparing all the combinations of classifiers and feature rankers, it was observed that LR performed best with 150 features selected by KS ranker. The models performed better with larger number of features and the best models have features 75 or more. Only the feature rankers MI, ROC, PRC, CS and KS shows enhanced efficiency as compared to no feature selection.

R. Mansour et al. [20] in their research used multiple sets of features for sentiment classification by using an ensemble classifier. The classification complexity comes out linear with the increase in feature set size. The ensemble is implemented on two features sets; one optimal set with 20000 features and other NRC data set with 4 million features. The feature set with selected 20000 features has shown relative $9.9 \%$ and $11.9 \%$ performance gain over 4 million feature set.

O. Abdelwahab et al. [21] in their research demonstrated the effect of training set size on accuracy of SVM and NB classifiers. The Python NLTK library is used for implementation of classifiers. The results show that there is a little increase in accuracy if training data increases from 20 to 90 to percent. So a moderate size data can be trained to get acceptable results.

S. Akter et al. [22] predicted the sentiment for the Facebook posts using a lexicon-based sentiment analysis technique. The data set used in the implementation is FOODBANK the Facebook group in Bangladesh. In the research a console is developed using C\# and Graph API is used to collect data.

M. Bouazizi et al. [23] proposed a new model for detecting the sarcasm using sentiment analysis of twitter data as micro blogging social networking sites are very useful in detecting sarcastic statements. A pattern-based sarcasm detection approach is used for twitter. A feature set with four relevant features for identifying different kinds of sarcasm is used and tweets are classified as non-sarcastic and sarcastic two classes. The model achieved an accuracy of $83.1 \%$ with $91.1 \%$ precision. SVM classifier is used and WEKA tool is used in implementation.

Grandin and Adan et al. [24] proposed a model Piegas for the sentiment of Portugal tweets. The Naïve Bayes classifier is implemented by using JavaScript and Ruby on Rails are used for the development of the system. The main requirement of the model is to develop a system with good usability and high precision.

Nádia et al. [25] proposed a new semi-supervised approach to solve the problem of cost of getting supervised data for machine learning. Unsupervised information retrieved from the similarity matrix created from unlabeled data is used with 
various classifiers in place of classified data. Similarity matrix can be used as a powerful knowledge extraction tool to get information from non-labeled data. The results of the proposed framework show the improved accuracy for Twitter sentiment classification by using unlabeled data.

A. Tripathy [26] implemented four machine learning classification algorithms SVM, NB, Maximum Entropy (ME) and Stochastic Gradient Descent (SGD) on IMDb data set for sentiment classification. These classification models are implemented on unigram, bigram and n-gram features and it is observed that if the value of $n$ is increased in n-gram after 2 than accuracy is decreased rather than increasing. For unigram and bigram accuracy is good but for trigram, four-gram, fivegram accuracy is decreased. Also, the use of count vectorizer technique and TF- IDF for converting the text into a matrix of weights, enhance the accuracy of classification.

A. Krouska et al. [27] in their research show the effect of preprocessing on the classification accuracy. The research also shows a major enhancement in result when IG is used for attribute selection. The research uses Unigram, Bigram and 13 gram feature vector. Preprocessing and feature selection enhance the accuracy. Unigram and 1-3 gram performed best among all.

K. Ali et al. [28] proposed SAaaS (Sentiment Analysis as a Service) framework to abstract sentiments of various social media information services. Public health surveillance related to social media based is done by using spatial attributes of social media users to find the location of disease outbreak. A new quality model is introduced to remove noise from the social media content. The real-world datasets from Twitter, Instagram, Reddit, news forum are used in the research. Sentistrength and Alchemy API tools are used in research. The Sentistrength tool is used for the analysis of short and informal text while Alchemy API for long and formal text.

A. U. Hassan et al. [29] In this paper, presented the method to detect the depression level of a person by fetching emotions from the social media text by using NLP and machine learning techniques on social media Twitter dataset and 20 newsgroups.

M. R. Huq et al. [30] used two techniques for sentiment analysis: First technique is a sentiment classification algorithm (SCA) based on KNN and the second is based on SVM. The research shows the comparative analysis of both the methods on the basis of recall, precision, accuracy, F-Score, TPR and FPR for 1000 tweets.

M. Ahmad [31] implemented Support Vector Machine (SVM) on two twitter pre-classified data sets for textual polarity detection. Recall, Precision and F-Measure are used for comparative analysis. The result shows that performance of SVM depends on the dataset itself. So it can be an area of research that what kind of classification algorithm is good for which kind of data set and what is the reason for that.

J. Brandon et al. [32] implemented twitter sentiment analysis to find the opinion of people for candidates in 2016 US Presidential elections. Lexicon based classifier and NB Machine learning classifiers are used on two data sets. One data set is a manually labeled Twitter data set and the other is an automatically labeled data set based on Hashtags and topic. A high correlation of 94 percent was found with polling data by using a moving average smoothing technique.

R. Wijayanti et al. [33] proposed an ensemble classifier based on a voting-based technique and used SVM, NB, LR (Logistic Regression) and Decision Tree classification algorithms for the implementation of proposed ensemble classifier. They used various feature representation techniques such as TF-IDF, sentiment lexicon score and term presence in their research. Ensemble classification results are proved to be better than individual machine learning classifiers, but ensemble accuracy highly depends on the selection of single classifiers used for creating the ensemble classifier.

Z. Jianqiang et al. [34] monitored the effect of six preprocessing techniques by using four classification algorithms (NB, SVM, RF, LR) and two feature selection methods. The result shows that accuracy is improved after using preprocessing techniques on the dataset. But removal of URL's, numbers and stop words hardly affects the accuracy, so they can be removed. Random deletion of words reduces the accuracy as the deleted word might be important in sentiment detection. NB and RF are more sensitive to the use of different pre-processing techniques.

Rahman et al.[35] analyzed the reliable decision making for a friend request to be accepted in Online Social Networks. Here, a quantitative study for analyzing the friend request has been carried out and the information regarding the social media websites were explained and information misuse of the other users and friends due to being deficient in trustworthy Friend Request Acceptance. In the research, a method is proposed for reliable friend request acceptance in Online Social Networks by finding out more details of the person who has sent the friend request.

Jianqiang et al. [36] proposed a method for opinion mining using deep convolution neural networks. Unsupervised learning is used for obtaining word embeddings by using a large set of Twitter data. The n-grams features combined with the word embeddings and polarity score extracted from sentiment lexicon are used for Twitter sentiment analysis. Sentiment classification labels were predicted after training the feature set with deep convolution network. GloVe-DCNN on the STSTd dataset performed best with accuracy $87.62 \%$.

K. Tago et al. [37] performed an analysis based on Twitter data using user relationships and analysis of emotional behaviors. Here, two dictionaries of emotional words are analyzed using the machine learning classifiers and keyword matching is used for calculating emotion scores. Moreover, with different settings, three experiments were designed and these are the user's average emotion scores that were calculated. Using all the emotional tweets, the average of emotion score is calculated after user of few emotional tweets was excluded. Brunner-Munzel test was used to evaluate emotional behaviors to user relationships. As per results, positive users participate more than negative users in building a relationship in some particular conditions.

In Ikoro, Victoria, et al. [38], sentiment analysis of UK energy consumers is done by using messages posted on 
Twitter. Big Six and three new entrant energy providers companies are compared on the basis of tweet sentiments. Two sentiment lexicons are used to maximize accuracy. As per results, consumers are more positive towards new companies and the use of multiple lexicons helps to improve the accuracy of sentiment analysis.

C. Troussas et al. [39] implemented four different ensemble techniques: bagging, Boosting, Voting and Stack based ensemble on three different data sets. Stack-based ensemble model is implemented by using NB, SVM, KNN and C4.5 as base classifiers and LR as a Meta classifier. The result shows that stack-based model surpasses the efficiency of other classifiers. Three datasets are used viz. OMD, HCR, STS-Gold. Stack based ensemble classifier performed best with an accuracy of $89.02 \%$ on STS-Gold dataset.

M. M. Fouad et al. [40] focused their research on the efficient classification of twitter data by combining NLP and data mining techniques. They implemented majority votingbased ensemble classification technique by using SVM, LR, NB classifiers and Information Gain (IG) feature selection technique. IG technique enhances the efficiency of classifier by selecting more appropriate features. The ensemble classifier also improves the accuracy, but if any one of the participant algorithms in ensemble does not suit the data set, then accuracy is decremented. Feature subset further enhanced with the use of emoticons does not enhance the efficiency of classification.

Y. Emre Isik et al. [41] also used stack-based ensemble classification techniques for sentiment classification of text. The ensemble is performed at two levels, one at feature selection level and other at classifier level; as a less accurate feature selection can lead to poor classification, so two techniques are used at feature selection level to reduce error and for enhanced feature selection. Two classification methods are used as an ensemble to enhance classification accuracy. The technique shows good results as compared to other machine learning classifiers.

F. T. Giuntini et al. [42] in their research perform the sentiment analysis on Facebook post. The aim of the research is to find the relevancy of emoticons used in the Facebook posts whether the emoticons match with the actual sentiment present in the post at six basic emotion levels. The paper proposed a 'Expectation Maximization algorithm' that finds correlation between the emoticons used in the tweet and the emotion class of the post. As per research, the use of emoticons as attribute enhances the result of classification of Twitter posts.

S. E. Saad et al. [43] used ordinal regression for twitter data sentiment analysis for twitter dataset provided by the NLTK. The algorithms used for opinion mining in the proposed model framework are SoftMax (Multinomial logistic regression), SVR (Support Vector Regression), DTs (Decision Trees), and RF (Random Forest). As per research, proposed framework can detect ordinal regression and decision tree proved to be the best from the above mentioned algorithms.

S. Vashishtha at al. [44] performed opinion mining of tweets by using three different lexicons and nine pubic twitter data sets, for classifying tweets at two and three levels of sentiments. The research proposed a fusion of multiple lexicons with fuzzy classification approach for enhanced classification. The nine datasets used in implementation are viz. The dataset used are Sanders Twitter Dataset, Nuclear Twitter Dataset, Apple Twitter Dataset, (STS-Test), Sentiment140, SemEval 2017, SemEval 2015 and Data used by Gilbert \& Hutto, 2014, SemEval 2016.

K. Elshakankery et al. [45] proposed a new hybrid approach named HILATSA by combining lexicon and machine learning approach. The proposed approach performed with an accuracy of $73.67 \%$ for three class classification and $83.73 \%$ for two class classification problem. Six different data sets used in the implementation are ASTD, Mini Arabic Tweets Sentiment Dataset, ArSAS, Arabic Gold Standard Twitter Data set, Syrian Tweets Corpus and Twitter dataset for Arabic Sentiment Analysis.

Martin-Domingo et al. [46] used machine learning classification for airport service quality analysis on London Heathrow airport's Twitter account dataset by using machine learning sentiment analysis technique. They used Theysay and Twinword tools for implementation. Theysay performed better than Twinword with 78.7 percent accuracy as compared to $69.6 \%$ of Theysay. The purpose of research is to generate a list of service attributes that reflect the ASQ and results reflect that additional attribute does not reflect more accurate ASQ prediction.

M. Naz at al. [47] in their research implemented an ensemble classification model by using two classifiers KNearest Neighbor and Naïve Bayes. They used two feature selection techniques: Forest Optimization algorithm (FOA) and minimum redundancy and maximum relevance (mRMR). FOA is used for feature selection and mRMR for the removal of irrelevant features. As per the results of the research, ensemble classifier combined with feature selection technique performed comparatively better than the individual machine learning algorithms. Results are further improved by using an ensemble of KNN, NB and SVM. It is also evident from the research that the hybrid of FOAKNN and FOA-NB has outperformed single KNN and NB classifiers. Accuracy is increased when FOA and nRMR feature selection techniques are applied. The Blitzer's dataset, retrieved from the UCI repository related to the reviews of electronic products, is used for the implementation of various classifiers in the research.

J. J. Bird et al. [48] proposed multiclass sentiment classification for five different levels of sentiments in a range from1-5 representing negative to positive score. Various single classifiers viz. OneR, MLP, NB, NBM, RT, J48, SMO SVM and ensemble classifiers named RF, AdaBoost (RT), Vote (RT, NBM, MLP), Vote (RF, MLP, NBM), AdaBoost (RF) are implemented. The research shows that the majority voting-based ensemble of NBM, RF, MLP performed best with $91.02 \%$ accuracy. In individual classifiers, RT (Random Tree) performed best with accuracy of 78.6\%. All ensemble methods outperformed single classifier.

M. Khader et al. [ 49] in their research show the effect of preprocessing techniques such as using tokenization, PoS tagging, removing stop words, URL, other users' mention, 
numbers and hashtags and lemmatization on Naïve Bayes machine learning classifier. Mapreduce of Hadoop is used for the implementation on Stanford twitter Sentiment data set. The proposed technique reflects an increase of 5\% accuracy yielding to $73 \%$ for NB classifier.

R. Ahujaa et al. [50] implemented six classifiers viz. Decision Tree, SVM, KNN RF, LR TF-IDF, NB by using two feature selection techniques $\mathrm{N}$-gram and TF-IDF on 'SSTweets' data set. The results show that TF-IDF feature selection show 3-4 \% increase in performance as compared to $\mathrm{N}$-gram feature.

M. bibi et al. [51] in their research proposed a new feature selection technique CAARIA "class association and attribute relevancy based imputation algorithm" that is proved to be better than IG and PC with an AUC (F-measure) value of 0.79. The research is performed on three twitter data sets HCR, SS-Tweet and FleTweetsPak on two machine learning classifiers SVM and NB by using WEKA tool. The newly proposed technique reduces feature dimension space by selecting tweets that have same class and carry useful information.

M. Bibi et al. [52] used hierarchical based clustering techniques named SL (single linkage), AL (average linkage) and CL (complete linkage) for the sentiment mining of twitter data. A combined framework architecture is built by using these three clustering techniques to select the best possible cluster with the help of using majority voting. The hierarchical clustering techniques proposed in the research are compared with k-means, SVM and NB classifiers. The outcome of research indicates that majority voting-based cooperative clustering is better in terms of quality of clusters but poor in term of time efficiency.

Z. Kermani et al. [53] used IDF, Term Frequency, sentiment scoring using lexicon dictionary SentiWordNet, semantic similarity for representing each feature weight of tweet in the feature vector. The percentage of contribution in the weight by each method is optimized and solved by genetic algorithm. The weight of feature obtained from all the four techniques are merged by using Einstein sum. SVM and multinomial NB classification methods are used on this weighted enhanced feature vector to classify tweets. Four Twitter data sets used for the implementation are Stanford testing dataset, Strict Obama McCain Debate dataset, STSGold and Obama-McCain Debate dataset.

Esraa A. Afify et al. [54] in their research aim to classify the Facebook account as fake or genuine, on the basis of content generated and finding the correlation between user generated content. Credibility of an account is decided at two levels. First binary classification is applied to classify account as fake or genuine. After that, credibility score of the genuine class is calculated by using Analytical Hierarchical Process. On the basis of that score account credibility is decided. The research used machine learning and deep learning techniques for the identification of Facebook profile credibility by using Scikit-learn and Keras with TensorFlow. Scikit-learn is used for the implementation of machine learning techniques and Keras with TensorFlow for implementing deep learning.

George S.R. et al. [55] proposed a framework for opinion prediction for a product or brand name in Facebook during social distancing by using machine learning algorithms and netnography. The study actually proposes a conceptual framework and suggested various tools used by different researchers for opinion mining of Facebook viz. netnography, Google analytics, tweetstats, brandwatch, Facebook insights, sematrica's lexalytics, Google alerts and people browser.

Most of the work aim to find out the sentiment related to service or product by using dictionary-based, Machine learning based or hybrid classifiers. The overall purpose is to enhance accuracy and efficiency of classification models. Different researches are performed on different data corpus. Different tools are used by researchers to observe the variations in the outcome. Table I summarizes the tool, technology, data corpus used and final outcome of all the papers included in the survey.

TABLE I. SUMMARY OF REVIEWED LITERATURE

\begin{tabular}{|c|c|c|c|c|}
\hline Author (Year) & Technique/ Approach & Tool Used & Data Corpus / Context & Results / Outcomes \\
\hline $\begin{array}{l}\text { M Whitehead et } \\
\text { al. [1] (2009) }\end{array}$ & $\begin{array}{l}\text { Ensemble classifiers: Bagging } \\
\text { and AdaBoost-r (KNN, } \\
\text { C4.5,SVM, MLP, RBF, LR) }\end{array}$ & WEKA & Twitter & $\begin{array}{l}\text { Ensemble classifier performed better, for } \\
\text { noisy data also. }\end{array}$ \\
\hline $\begin{array}{l}\text { Kumar et al. [2] } \\
\text { (2010) }\end{array}$ & $\begin{array}{l}\text { Evolution and analysis of Social } \\
\text { Networks in three different size } \\
\text { networks by Graph Theory. }\end{array}$ & $\begin{array}{l}\text { Representation and } \\
\text { analysis of social network } \\
\text { as timegraph. }\end{array}$ & $\begin{array}{l}\text { Yahoo!s } 360 \text { social } \\
\text { network and Flickr photo } \\
\text { sharing application. }\end{array}$ & $\begin{array}{l}\text { Mention the evolution of social network } \\
\text { components of different sizes and shows } \\
\text { "star" as most prevailing structure of } \\
\text { social network. }\end{array}$ \\
\hline $\begin{array}{l}\text { A Agarwal et al. } \\
\text { [3] (2011) }\end{array}$ & $\begin{array}{l}\text { Tree kernels with POS specific } \\
\text { polarity features }\end{array}$ & Python & $\begin{array}{l}\text { 11,875 manually labeled } \\
\text { tweets }\end{array}$ & $\begin{array}{l}\text { Maximum tweets are classified in neutra } \\
\text { class. }\end{array}$ \\
\hline $\begin{array}{l}\text { Bae Y. et al. [4] } \\
\text { (2011) }\end{array}$ & $\begin{array}{l}\text { Dictionary based classification } \\
\text { using LIWC2007 }\end{array}$ & Twitter API, LIWC2007 & Twitter & $\begin{array}{l}\text { Sentiment analysis of twitter data related } \\
\text { to famous personalities as negative or } \\
\text { positive. }\end{array}$ \\
\hline $\begin{array}{l}\text { ACES Lima et al. } \\
\text { [5] (2012) }\end{array}$ & Naïve Bayes & Twitter4J Library, JAVA & $\begin{array}{l}\text { Twitter Dataset: Real Time } \\
\text { Tweets. }\end{array}$ & $\begin{array}{l}\text { Sentiment classification on the basis of } \\
\text { emoticons, sentiment based words or } \\
\text { hybrid. Hybrid approach enhances } \\
\text { accuracy. }\end{array}$ \\
\hline $\begin{array}{l}\text { F Neri et al. [6] } \\
(2012)\end{array}$ & $\begin{array}{l}\text { Bayesian method and K-Means } \\
\text { algorithm }\end{array}$ & iSyn Semantic Center & $\begin{array}{l}\text { Facebook about newscasts } \\
\text { (La7 and Rai1 news } \\
\text { programs) }\end{array}$ & $\begin{array}{l}\text { Show importance of Facebook for online } \\
\text { marketing. }\end{array}$ \\
\hline
\end{tabular}




\begin{tabular}{|c|c|c|c|c|}
\hline $\begin{array}{l}\text { H Kang et al. [7] } \\
(2012)\end{array}$ & Naïve Bayes, SVM & WEKA & $\begin{array}{l}70000 \text { review documents } \\
\text { from restaurant sites }\end{array}$ & $\begin{array}{l}\text { Proposed enhanced NB algorithm. } \\
\text { Enhancement in precision and accuracy in } \\
\text { proposed algorithm. }\end{array}$ \\
\hline $\begin{array}{l}\text { M Ghiassi et al. } \\
\text { [8] (2013) }\end{array}$ & $\begin{array}{l}\text { Supervised learning technique } \\
\text { using n-gram statistical analysis }\end{array}$ & SVM and DAN2 & $\begin{array}{l}\text { Real time collected for } \\
\text { keyword 'Justin Bieber' }\end{array}$ & $\begin{array}{l}\text { Proposed model performed better than } \\
\text { SVM with an accuracy of } 95.1 \% \text {. }\end{array}$ \\
\hline $\begin{array}{l}\text { Hassan et al. [9] } \\
\text { (2013) }\end{array}$ & $\begin{array}{l}\text { Bootstrap ensemble framework } \\
\text { (BPEF). }\end{array}$ & $\begin{array}{l}\text { FRN, Viralheat, Popular } \\
\text { Tool, Light side, Lymbix, } \\
\text { Sentistrength, Sentiment } \\
140\end{array}$ & $\begin{array}{l}\text { Twitter dataset: } \\
\text { Telco, Tech, Pharma }\end{array}$ & $\begin{array}{l}\text { SIMS module of BPEF was able to } \\
\text { extract models with higher efficiency. }\end{array}$ \\
\hline $\begin{array}{l}\text { E Haddia et al. } \\
\text { [10] (2013) }\end{array}$ & $\begin{array}{l}\text { Preprocessing Methods. } \\
\text { Classifier SVM. } \\
\text { Feature wt. using TD-IDF, FF, } \\
\text { FP. }\end{array}$ & 'e1071' in R Tool & $\begin{array}{l}\text { movie reviews, DAT-1400, } \\
\text { Dat-2000 }\end{array}$ & $\begin{array}{l}\text { Improvement observed in accuracies of } \\
\text { TD-IDF matrix from } 78.33 \text { to } 81.5 \text {, in } \\
\text { Metric FF } 76.33 \text { to } 83 \text { and in FP matrix } \\
82.33 \text { to } 83 \text {. }\end{array}$ \\
\hline $\begin{array}{l}\text { G Patil et. al [11] } \\
\text { (2014) }\end{array}$ & $\begin{array}{l}\text { ANN, SVM } \\
\text { And TF-IDF }\end{array}$ & --- & Twitter & $\begin{array}{l}\text { SVM Performed better than ANN. SVM } \\
\text { use few irrelevant feature and High dim. } \\
\text { Feature space. }\end{array}$ \\
\hline $\begin{array}{l}\text { Inoshika et al. } \\
\text { [12] (2014) }\end{array}$ & $\begin{array}{l}\text { Machine Learning: SVM, } \\
\text { Decision Tree, RF, J48, CART. } \\
\text { Feature Selection: feed forward } \\
\text { and feedback selection, IG, Chi } \\
\text { square }\end{array}$ & ---- & $\begin{array}{l}\text { Twitter Data set: Data by } \\
\text { Ada Derana, News First, } \\
\text { Ceylon Today, Lanka } \\
\text { Breaking News, ITN. }\end{array}$ & $\begin{array}{l}\text { Proposed a new information theory based } \\
\text { feature ranker named Ratio Method that } \\
\text { result in improved efficiency. }\end{array}$ \\
\hline $\begin{array}{l}\text { Bac Le et al. [13] } \\
\text { (2015) }\end{array}$ & $\begin{array}{l}\text { Machine Learning :SVM and NB } \\
\text { IG, Bigram, Object-oriented } \\
\text { extraction for feature selection }\end{array}$ & $\begin{array}{l}\text { AlchemyAPI, Scikit- } \\
\text { Learn tool }\end{array}$ & $\begin{array}{l}\text { Twitter : AlchemyAPI, } \\
\text { Zemanta, OpenCalais }\end{array}$ & Accuracy enhanced. \\
\hline $\begin{array}{l}\text { BS Dattu et al. } \\
\text { [14] (2015) }\end{array}$ & SVM , NB & $\begin{array}{l}\text { TwitterSentiment and } \\
\text { SentiStrength }\end{array}$ & $\begin{array}{l}\text { Real Time Twitter Data } \\
\text { related to 'NFL teams' }\end{array}$ & $\begin{array}{l}\text { SVM performed better than NB and NB is } \\
\text { insensitive to unbalanced data. }\end{array}$ \\
\hline $\begin{array}{l}\text { O Kolchyna et al. } \\
\text { [15], (2015) }\end{array}$ & $\begin{array}{l}\text { Lexicon-based and machine } \\
\text { learning (SVM, NB) }\end{array}$ & WEKA & $\begin{array}{l}\text { SemEval-2013 } \\
\text { competition, task 2-B }\end{array}$ & $\begin{array}{l}\text { Combining lexicon with SVM and NB } \\
\text { enhance accuracy. }\end{array}$ \\
\hline $\begin{array}{l}\text { J Prusa et al. [16] } \\
\text { (2015) }\end{array}$ & $\begin{array}{l}\text { Ensemble Technique : Bagging } \\
\text { and Boosting using } 7 \text { base } \\
\text { learners ( } 5 N N, \text { C4.5D, C } 4.5 N \text {, } \\
\text { MLP, LR, SVM, RBF). }\end{array}$ & WEKA & $\begin{array}{l}\text { Sentiment140 (S_3000, } \\
\text { S_359) }\end{array}$ & $\begin{array}{l}\text { Ensemble Classifier enhances accuracy. } \\
\text { Enhancement in result is less uniform for } \\
\text { smaller size data set. }\end{array}$ \\
\hline $\begin{array}{l}\text { K.L Devi et al. } \\
\text { [17] (2015) }\end{array}$ & $\begin{array}{l}\text { Ensemble classifiers: Bagging } \\
\text { and Boosting (SVM, NB, ME) } \\
\text { Feature Selection using MI and } \\
\text { Chi-square }\end{array}$ & ---- & $\begin{array}{l}\text { Twitter dataset: SemEval } \\
\text { 2013, Task } 9\end{array}$ & $\begin{array}{l}\text { Ensemble based learners produce improve } \\
\text { accuracy than base learners. }\end{array}$ \\
\hline $\begin{array}{l}\text { Y Wan et al. [18] } \\
\text { (2015) }\end{array}$ & $\begin{array}{l}\text { Majority voting ensemble( NB, } \\
\text { SVM, Bayesian Network, RF and } \\
\text { C4.5) and IG Feature selection }\end{array}$ & WEKA & $\begin{array}{l}12864 \text { tweets related to } \\
\text { airline service Twitter } \\
\text { dataset. }\end{array}$ & $\begin{array}{l}\text { Ensemble outperformed with an accuracy } \\
\text { of } 91.7 \% \text {. } \\
\text { RF learner was best in machine learners } \\
\text { with accuracy } 90.8 \% \text {. }\end{array}$ \\
\hline $\begin{array}{l}\text { J Prusa et al. [19] } \\
\text { (2015) }\end{array}$ & $\begin{array}{l}\text { Four classifiers(5-NN, C4.5, LR, } \\
\text { MLP) } \\
10 \text { feature selection methods: CS, } \\
\text { GI, KS, MI, PR, PRC, ROC, } \\
\text { S2N, SAM, WRS. }\end{array}$ & WEKA & $\begin{array}{l}\text { Twitter Dataset: } \\
\text { Sentiment140 }\end{array}$ & $\begin{array}{l}\text { Best feature selection methods - CS and } \\
\text { MI. Best feature set size - } 100 \text { to } 200 \text {. } \\
\text { CS, MI, PRC, KS and ROC resulted in } \\
\text { performance enhancement in comparison } \\
\text { to using no feature selection }\end{array}$ \\
\hline $\begin{array}{l}\text { R Mansour et al. } \\
\text { [20] (2015) }\end{array}$ & $\begin{array}{l}\text { Ensemble Classification. Feature } \\
\text { selection. NCR Feature set, LLR } \\
\text { Feature selection. }\end{array}$ & $\begin{array}{l}\text { Natural Language Toolkit } \\
\text { (NLTK) }\end{array}$ & $\begin{array}{l}\text { Twitter Dataset: } \\
\text { SemEval and CrowdScale }\end{array}$ & $\begin{array}{l}\text { Performance gain of } 9.9 \% \text { on CrowdScale } \\
\text { and } 11.9 \% \text { on SemEval. }\end{array}$ \\
\hline $\begin{array}{l}\text { O Abdelwahab et } \\
\text { al. [21] (2015) }\end{array}$ & SVM and NB & Python NLTK library & SEMEVAL 2014 & $\begin{array}{l}\text { SVM is more Robust than NB but NB is } \\
\text { faster comparatively. } \\
\text { Increase in training set size after } 20 \% \\
\text { have very little effect on accuracy } \\
\text { enhancement. }\end{array}$ \\
\hline $\begin{array}{l}\text { S Akter et al. [22] } \\
\text { (2016) }\end{array}$ & $\begin{array}{l}\text { Lexicon Based Approach / } \\
\text { Dictionary Based Approach. }\end{array}$ & Graph API, C\# & $\begin{array}{l}\text { FOODBANK: Facebook } \\
\text { group in Bangladesh }\end{array}$ & $\begin{array}{l}\text { Identified sentiment behind a status post } \\
\text { of Facebook by using lexicon based } \\
\text { approach. }\end{array}$ \\
\hline $\begin{array}{l}\text { M Bouazizi et al. } \\
\text { [23] (2016) }\end{array}$ & SVM & $\begin{array}{l}\text { WEKA and OpenNLP, } \\
\text { Gate Twitter partof- } \\
\text { speech tagger, }\end{array}$ & Twitter & $\begin{array}{l}\text { Sarcasm Detection: Accuracy of } 83.1 \% \\
\text { with to } 91.1 \% \text { precision. }\end{array}$ \\
\hline $\begin{array}{l}\text { P Grandin et al. } \\
\text { [24] (2016) }\end{array}$ & NB & $\begin{array}{l}\text { JavaScript and Ruby on } \\
\text { Rails }\end{array}$ & Twitter & $\begin{array}{l}\text { Sentiment classification of Portugal } \\
\text { tweets, Good Accuracy with improved } \\
\text { classification time. }\end{array}$ \\
\hline $\begin{array}{l}\text { Nádia et al. [25] } \\
\text { (2016) }\end{array}$ & $\begin{array}{l}\text { Hybrid (Classification and } \\
\text { Clustering Ensembles) : Semi- } \\
\text { supervised approach (Labeled and } \\
\text { Unlabeled data), SVM, Lexicon } \\
\text { Based }\end{array}$ & ---- & $\begin{array}{l}\text { SMS2013, Twitter2014, } \\
\text { Twitter Sarcasm 2014, } \\
\text { LiveJournal, Twitter2013. }\end{array}$ & $\begin{array}{l}\text { Proposed framework shows the improved } \\
\text { accuracy }(80 \%) \text {. }\end{array}$ \\
\hline
\end{tabular}




\begin{tabular}{|c|c|c|c|c|}
\hline $\begin{array}{l}\text { A Tripathy et al. } \\
\text { [26] (2016) }\end{array}$ & $\begin{array}{l}\text { SVM, NB, Maximum Entropy } \\
\text { and Stochastic Gradient Descent. } \\
\text { Features: unigram, bigram, } \\
\text { Trigram and n-gram features. }\end{array}$ & ---- & $\begin{array}{l}\text { Twitter } \\
\text { IMDb data set }\end{array}$ & $\begin{array}{l}\text { Up to bigram feature set accuracy } \\
\text { enhances, After that for tri, four or five } \\
\text { gram accuracy of decreases. A } \\
\text { combination of Bi gram, Tri gram with } \\
\text { POS also worked well. } \\
\text { Unigram + Bigram (ME) - 88.42 } \\
\text { Uni + Bi + Trigram (ME) - } 83.36 \\
\text { Uni + Bigram (SVM) - 88.884 } \\
\text { Uni+Bi +Trigram (SVM) - 88.944 } \\
\text { Bigram (SGD) - 95 }\end{array}$ \\
\hline $\begin{array}{l}\text { A Krouska et al. } \\
\text { [27] (2016) }\end{array}$ & $\begin{array}{l}\text { Preprocessing Methods. } \\
\text { IG Feature Selection. Uni, Bi and } \\
\text { 1-3 gram features. } \\
\text { Machine Learners - NB, KNN, } \\
\text { SVM, C4.5. }\end{array}$ & $\begin{array}{l}\text { Snowball stemmer } \\
\text { library, Rainbow list }\end{array}$ & $\begin{array}{l}\text { Twitter } \\
\text { OMD } \\
\text { HCR } \\
\text { STS-GOLD }\end{array}$ & $\begin{array}{l}\text { Feature extraction improve accuracy. } \\
\text { unigram and 1-to-3-grams perform better. }\end{array}$ \\
\hline $\begin{array}{l}\text { K Ali et al. [28] } \\
\text { (2017) }\end{array}$ & $\begin{array}{l}\text { SAaaS Model using spatio- } \\
\text { temporal properties and Lexicon } \\
\text { classifier }\end{array}$ & $\begin{array}{l}\text { Sentistrength and } \\
\text { Alchemy API . } \\
\text {.Net framework by using } \\
\text { ASP.Net/C\# }\end{array}$ & $\begin{array}{l}\text { Real world datasets from } \\
\text { twitter, Instagram, Reddit, } \\
\text { news forum }\end{array}$ & $\begin{array}{l}\text { Identified sentiment and location of } \\
\text { disease outbreak. }\end{array}$ \\
\hline $\begin{array}{l}\text { AU Hassan et al. } \\
\text { [29](2017) }\end{array}$ & $\begin{array}{l}\text { Machine Learning } \\
\text { classifiers(SVM, NB, Maximum } \\
\text { Entropy) Binary and Multiclass } \\
\text { classification, Voting }\end{array}$ & ---- & $\begin{array}{l}\text { twitter dataset and } \\
\text { 20newsgroups }\end{array}$ & $\begin{array}{l}\text { Detect the depression level of users. SVM } \\
\text { performed better than NB. SVM - } 91 \% \text {, } \\
\text { NB - } 83 \% \text {, ME - } 80 \% \text {. }\end{array}$ \\
\hline $\begin{array}{l}\text { MR Huq et al. } \\
\text { [30] (2017) }\end{array}$ & k-nearest neighbor, SVM & Java language & Twitter & $\begin{array}{l}\text { KNN with normalization and keyword } \\
\text { base( } 5 \text { features) performed good. }\end{array}$ \\
\hline $\begin{array}{l}\text { M Ahmad et al. } \\
\text { [31] (2017) }\end{array}$ & SVM & WEKA & $\begin{array}{l}\text { Twitter Dataset related to } \\
\text { self-driving cars and apple } \\
\text { products }\end{array}$ & $\begin{array}{l}\text { Performance of SVM highly depends on } \\
\text { Dataset. }\end{array}$ \\
\hline $\begin{array}{l}\text { J Brandon et al. } \\
\text { [32] (2017) }\end{array}$ & $\begin{array}{l}\text { Lexicon-based and machine } \\
\text { learning }\end{array}$ & $\begin{array}{l}\text { National Language } \\
\text { Toolkit (NLTK) }\end{array}$ & Twitter & $\begin{array}{l}\text { High correlation of } 94 \text { percent was found } \\
\text { with polling data. }\end{array}$ \\
\hline $\begin{array}{l}\text { R Wijayanti et al. } \\
\text { [33] (2017) }\end{array}$ & $\begin{array}{l}\text { Voting based ensemble technique } \\
\text { (NB, SVM, decision tree, LR) } \\
\text { and feature selection using TF- } \\
\text { IDF, sentiment lexicon score and } \\
\text { term presence }\end{array}$ & ---- & $\begin{array}{l}\text { Twitter: Indonesian Twitter } \\
\text { messages, Indonesian } \\
\text { online marketplaces }\end{array}$ & $\begin{array}{l}\text { Ensemble classifier enhance efficiency } \\
\text { (accuracy - 91.59\% and F1-score - } \\
91.59 \% \text { ) but highly depend on base } \\
\text { classifiers. }\end{array}$ \\
\hline $\begin{array}{l}\text { Z Jianqiang et al. } \\
\text { [34] (2017) }\end{array}$ & $\begin{array}{l}\text { Six Preprocessing Methods. } \\
\text { Machine Learning Classifiers - } \\
\text { NB, LR, SVM, RF. }\end{array}$ & $\begin{array}{l}\text { GridSearch to find } \\
\text { optimal parameters. } \\
\text { scikit-learn for classifier. }\end{array}$ & $\begin{array}{l}\text { Twitter Dataset: } \\
\text { STS-Gold, SE-Twitter, } \\
\text { SemEval2014, SS-Twitter, } \\
\text { STS-test. }\end{array}$ & $\begin{array}{l}\text { Removal of URL's, stop words and } \\
\text { numbers hardly affects the accuracy. } \\
\text { Random deletion of word reduces the } \\
\text { accuracy. NB and RF are more sensitive } \\
\text { to use of different pre processing } \\
\text { techniques. }\end{array}$ \\
\hline $\begin{array}{l}\text { Rahman et al. [35] } \\
\text { (2018) }\end{array}$ & $\begin{array}{l}\text { Tree based algorithm, Depth } \\
\text { search based algorithms. }\end{array}$ & T-Test & $\begin{array}{l}\text { Facebook Accounts of } \\
\text { UMP students }\end{array}$ & Detect reliable friend request. \\
\hline $\begin{array}{l}\text { Jianqiang et al. } \\
\text { [36] (2018) }\end{array}$ & $\begin{array}{l}\text { Deep convolution neural } \\
\text { networks. BoW-SVM and BoW- } \\
\text { LR }\end{array}$ & ---- & $\begin{array}{l}\text { Twitter Data Sets: STSTd, } \\
\text { SemEval2014 Task9, } \\
\text { STSGd, SED, SSTd }\end{array}$ & $\begin{array}{l}\text { GloVe-DCNN on the STSTd dataset } \\
\text { performed best with accuracy } 87.62 \% \text {. }\end{array}$ \\
\hline $\begin{array}{l}\text { K Tago et al. [37] } \\
\text { (2018) }\end{array}$ & Machine learning & $\begin{array}{l}\text { T Test, Brunner-Munzel } \\
\text { test }\end{array}$ & $\begin{array}{l}\text { Twitter: Five thousand } \\
\text { twitter accounts by using } \\
\text { Twitter API. }\end{array}$ & $\begin{array}{l}\text { As per results positive user participate } \\
\text { more than negative users in building } \\
\text { relationship in some particular conditions. }\end{array}$ \\
\hline $\begin{array}{l}\text { V Ikoro, et al. } \\
\text { [38] (2018) }\end{array}$ & Lexicon Based & ---- & $\begin{array}{l}\text { Twitter : Tweets of UK } \\
\text { energy consumers }\end{array}$ & $\begin{array}{l}\text { Consumers are more positive towards } \\
\text { new companies and Multiple lexicon help } \\
\text { to improve accuracy of sentiment } \\
\text { analysis. }\end{array}$ \\
\hline $\begin{array}{l}\text { C Troussas et al. } \\
{[39]} \\
(2018)\end{array}$ & $\begin{array}{l}\text { Voting base ensemble, Bagging } \\
\text { and Boosting, Stack base } \\
\text { ensemble (NB, SVM, KNN and } \\
\text { C } 4.5 \text { ) } \\
\text { LR as Meta classifier }\end{array}$ & WEKA & $\begin{array}{l}\text { Twitter } \\
\text { OMD, HCR, STS-Gold }\end{array}$ & $\begin{array}{l}\text { Stack base ensemble performed best with } \\
\text { accuracy } 89.02 \% \text { in case of STS-Gold } \\
\text { dataset. }\end{array}$ \\
\hline $\begin{array}{l}\text { MM Fouad et al. } \\
\text { [40] (2018) }\end{array}$ & $\begin{array}{l}\text { Majority voting based ensemble } \\
\text { technique using SVM, LR, NB } \\
\text { classifiers. IG feature selection }\end{array}$ & $\begin{array}{l}\text { Java (Stanford Core NLP } \\
\text { library) for feature } \\
\text { extraction } \\
\text { RapidMiner }\end{array}$ & $\begin{array}{l}\text { Stanford-1K, Stanford-3K, } \\
\text { Sanders, HCR }\end{array}$ & $\begin{array}{l}\text { Ensemble classifier enhances efficiency } \\
\text { but highly depend on base classifiers. IG } \\
\text { selection boosted accuracy. }\end{array}$ \\
\hline
\end{tabular}




\begin{tabular}{|c|c|c|c|c|}
\hline $\begin{array}{l}\text { Y Emre Isik et al. } \\
\text { [41] (2018) }\end{array}$ & $\begin{array}{l}\text { Stack base ensemble } \\
\text { classification, Ensemble at feature } \\
\text { selection level. }\end{array}$ & ---- & Twitter & $\begin{array}{l}\text { Enhanced accuracy than machine } \\
\text { learners. }\end{array}$ \\
\hline $\begin{array}{l}\text { FT Giuntini et al. } \\
\text { [42] (2019) }\end{array}$ & $\begin{array}{l}\text { Expectation Maximization } \\
\text { algorithm }\end{array}$ & Lime Survey tool, & Facebook & $\begin{array}{l}\text { Relevancy of emoticons used in the } \\
\text { Facebook posts }\end{array}$ \\
\hline $\begin{array}{l}\text { SE Saad et al. } \\
\text { [43] (2019) }\end{array}$ & $\begin{array}{l}\text { SoftMax (Multinomial logistic } \\
\text { regression), SVR(Support Vector } \\
\text { Regression), DTs(Decision } \\
\text { Trees), and RF (Random Forest) }\end{array}$ & Python software & $\begin{array}{l}\text { Twitter dataset provided by } \\
\text { the NLTK }\end{array}$ & Decision tree proved to be the best. \\
\hline $\begin{array}{l}\text { S Vashishtha at al. } \\
\text { [44] (2019) }\end{array}$ & $\begin{array}{l}\text { Unsupervised Fuzzy } \\
\text { Classification, SVM. } \\
\text { Lexicon: SentiWordNet, AFINN, } \\
\text { AFINN }\end{array}$ & Python & $\begin{array}{l}\text { Twitter Dataset : } \\
\text { Sanders Twitter Dataset, } \\
\text { Nuclear Twitter Dataset, } \\
\text { Apple Twitter Dataset, } \\
\text { (STS-Test), Sentiment140, } \\
\text { SemEval 2017, SemEval } \\
2015 \text { and Data used by } \\
\text { Gilbert \& Hutto, 2014, } \\
\text { SemEval 2016. }\end{array}$ & $\begin{array}{l}\text { The method based on Fuzzy Rule } \\
\text { performed better than SVM. VADER and } \\
\text { AFINN lexicon outperformed as } \\
\text { compared to SentiWordNet. }\end{array}$ \\
\hline $\begin{array}{l}\text { K Elshakankery et } \\
\text { al. [45] (2019) }\end{array}$ & $\begin{array}{l}\text { HILATSA as Combination of } \\
\text { lexicon based approach and } \\
\text { machine learning classifiers } \\
\text { (SVM, L2 Logistic Regression, } \\
\text { RNN) }\end{array}$ & $\begin{array}{l}\text { JAVA } \\
\text { Libraries- LIBSVM, } \\
\text { DL4J and LIBLINEAR }\end{array}$ & $\begin{array}{l}\text { ASTD, Mini Arabic } \\
\text { Sentiment Tweets Dataset, } \\
\text { ArSAS, Arabic Gold } \\
\text { Standard Twitter Data set, } \\
\text { Syrian Tweets Corpus and } \\
\text { Twitter dataset }\end{array}$ & $\begin{array}{l}\text { The proposed approach with accuracy: } \\
73.67 \% \text { - 3-class classification } \\
83.73 \% \text { - 2-class classification }\end{array}$ \\
\hline $\begin{array}{l}\text { Martin-Domingo } \\
\text { et al. [46] (2019) }\end{array}$ & Machine learning & $\begin{array}{l}\text { Twitter Archive, Theysay } \\
\text { and Twinword }\end{array}$ & $\begin{array}{l}\text { Twitter : London Heathrow } \\
\text { airport's Twitter account } \\
\text { dataset }\end{array}$ & $\begin{array}{l}\text { Theysay performed better than Twinword } \\
\text { with } 78.7 \text { percent }\end{array}$ \\
\hline $\begin{array}{l}\text { M Naz at al. [47] } \\
\text { et al. (2019) }\end{array}$ & $\begin{array}{l}\text { Ensemble Technique using K- } \\
\text { Nearest neighbor NB and SVM. } \\
\text { FOA and mRMR feature } \\
\text { selection algorithm. }\end{array}$ & MATLAB & $\begin{array}{l}\text { Twitter : Blitzer’s dataset, } \\
\text { retrieved from UCI } \\
\text { repository }\end{array}$ & $\begin{array}{l}\text { Ensemble of KNN, NB, SVM with } \\
\text { feature selection enhances accuracy. }\end{array}$ \\
\hline $\begin{array}{l}\text { JJ Bird et al. [48] } \\
\text { (2019) }\end{array}$ & $\begin{array}{l}\text { OneR, MLP, NB, NBM, RT, J48, } \\
\text { SMO SVM, } \\
\text { Ensemble classifiers: RF, Vote } \\
\text { (RF, MLP, NBM), AdaBoost } \\
\text { (RT), AdaBoost (RF), Vote (RT, } \\
\text { NBM, MLP). }\end{array}$ & JAVA & $\begin{array}{l}\text { Twitter : London based } \\
\text { restaurant tweets from } \\
\text { TripAdvisor }\end{array}$ & $\begin{array}{l}\text { Vote (RF, NBM, MLP) performed best } \\
\text { with } 91.02 \% \text { accuracy. }\end{array}$ \\
\hline $\begin{array}{l}\text { M Khader et al. [ } \\
\text { 49] (2019) }\end{array}$ & $\begin{array}{l}\text { Machine Learning Classifier: } \\
\text { Naïve Bayes } \\
\text { PoS Tagging, lemmatization, } \\
\text { weighting terms. }\end{array}$ & $\begin{array}{l}\text { Apache OpenNLP of } \\
\text { MapReduce (Hadoop). }\end{array}$ & $\begin{array}{l}\text { Stanford Twitter Sentiment } \\
\text { data set }\end{array}$ & $\begin{array}{l}5 \% \text { increase in accuracy for Stanford } \\
\text { Sentiment data set. }\end{array}$ \\
\hline $\begin{array}{l}\text { R Ahujaa et al. } \\
\text { [50] (2019) }\end{array}$ & $\begin{array}{l}\text { Machine Learning Classifier: } \\
\text { Decision Tree, SVM, KNN RF, } \\
\text { LR TF-IDF, NB. } \\
\text { Feature selection: N-gram TF- } \\
\text { IDF }\end{array}$ & --- & $\begin{array}{l}\text { Twitter Dataset: } \\
\text { SS-Tweets }\end{array}$ & $\begin{array}{l}\text { TF-IDF performance is } 3-4 \% \text { higher than } \\
\mathrm{N} \text {-gram feature. }\end{array}$ \\
\hline $\begin{array}{l}\text { M bibi et al. [51] } \\
\text { (2019) }\end{array}$ & $\begin{array}{l}\text { Machine Learning: SVM, NB } \\
\text { Feature Selection : IG and PC }\end{array}$ & WEKA & $\begin{array}{l}\text { Twitter Dataset: } \\
\text { HCR, SS-Tweet, } \\
\text { FleTweetsPak }\end{array}$ & $\begin{array}{l}\text { CAARIA: Proposed feature selection } \\
\text { technique. } \\
\text { CAARIA proved to be better than IG and } \\
\text { PC with AUC (F-measure) value } 0.79 \text {. }\end{array}$ \\
\hline $\begin{array}{l}\text { M Bibi et al. [52] } \\
(2020)\end{array}$ & $\begin{array}{l}\text { Clustering and classification } \\
\text { technique using majority voting, } \\
\text { k-means, SVM and NB classifiers }\end{array}$ & WEKA & $\begin{array}{l}\text { Twitter Data Sets : } \\
\text { HCR - Health Care } \\
\text { Reform, } \\
\text { SS-Tweet - Sentiment } \\
\text { Strength Twitter Dataset } \\
\text { STS-Test - Stanford } \\
\text { Twitter Sentiment Test Set }\end{array}$ & $\begin{array}{l}\text { Majority voting based cooperative } \\
\text { clustering is better in terms of quality }\end{array}$ \\
\hline $\begin{array}{l}\text { Z Kermani et al. } \\
\text { [53] (2020) }\end{array}$ & $\begin{array}{l}\text { Machine Learning-based } \\
\text { approach and genetic algorithm } \\
\text { for calculating feature weight. }\end{array}$ & $\begin{array}{l}\text { NLTK, Scikit packages of } \\
\text { Python software }\end{array}$ & $\begin{array}{l}\text { Twitter Data Sets : } \\
\text { Stanford test data corpus, } \\
\text { STS-Gold, Strict Obama } \\
\text { McCain Debate, Obama } \\
\text { McCain Debate Datasets. }\end{array}$ & $\begin{array}{l}\text { Efficiency of proposed method TSA is } \\
\text { improved but time complexity is poor, } \\
\text { specially for big twitter data sets. }\end{array}$ \\
\hline $\begin{array}{l}\text { EA Afify et al. [ } \\
\text { 54] (2020) }\end{array}$ & $\begin{array}{l}\text { Machine Learning, } \\
\text { Deep Learning. }\end{array}$ & $\begin{array}{l}\text { Machine Learning-Scikit- } \\
\text { learn, Deep Learning- } \\
\text { Keras with TensorFlow }\end{array}$ & Facebook & $\begin{array}{l}\text { Evaluate Facebook profile credibility. } \\
\text { Identify fake and genuine users. }\end{array}$ \\
\hline $\begin{array}{l}\text { SR George et al. } \\
\text { [55] (2021) }\end{array}$ & Machine Learning Classifier. & Netnography & Facebook & $\begin{array}{l}\text { Proposed conceptual framework for } \\
\text { Facebook opinion mining }\end{array}$ \\
\hline
\end{tabular}




\section{SURVEY OUTCOMES}

In the present survey paper we have conducted a systematic survey of literature related to social networking site's sentiment analysis or opinion mining. From 2009 to 2021 several researches have been conducted and technology evolved from simple dictionary-based sentiment prediction to ensemble, fuzzy, deep learning and neural based sentiment analysis. Detailed outcomes of researches are mentioned in Table I with tools and technologies used. Various advancements occur in the area of attribute selection, preprocessing and classifiers used. Data becomes big and technology changed as per data need. From the detailed survey of included literature, it has been observed that Naïve Bayes and SVM are the most explored machine learning classifiers. Lots of work has been conducted in the area of ensemble classification technique. The most of the researchers are attracted by Twitter opinion mining and Facebook is the second most explored social media platform. Sentiment 140 is quite a frequently used data corpus. WEKA, RStudio, Python and NLTK are used in several research implementations. Facebook and Twitter are relatively less unstructured and sentiment analysis does not include image, audio or video. As media content can be in any one of these forms also, so sentiment extraction from these resources can be quite interesting and important but challenging too. So lots of work has been done on text sentiment analysis and most of them target to improve efficiency of classification.

\section{CONCLUSION}

The manuscript presents a survey conducted on 55 different research papers related to social networking site's sentiment analysis. The survey reflected the evolution and enhancement of tools and technologies from 2009 to 2021 for sentiment analysis. Twitter is the maximum explored social networking site in the area of sentiment analysis. WEKA, RStudio and NLTK are most popular tools used by researchers. The area of text sentiment classification has been widely explored with the use of advanced classification techniques, big data technology, better simulation tools and most of them target to improve efficiency of sentiment classification. A new scope can be sentiment analysis from images, audio and video content as this area is comparatively untouched and huge repository of audio and video content is available on social media.

\section{REFERENCES}

[1] M. Whitehead and L. Yaeger, "Sentiment Mining Using Ensemble Classification Models", Springer "Innovations and Advances in Computer Sciences and Engineering”, Dec 2009, pp. 509-514.

[2] R. Kumar, J. Novak, A. Tomkins, "Structure and evolution of online social networks", in 'Link mining: models, algorithms, and applications', Springer, pp. 337- 357, 2010.

[3] A. Agarwal, B. Xie, I. Vovsha, O. Rambow, R. Passonneau, "Sentiment Analysis of Twitter Data”, LSM '11 Proceedings of the workshop on Languages in Social Media, Columbia University New York, ISBN: 978-1-932432-96-1, pp. 30-38, 2011.

[4] Y. Bae, H. Lee, "A Sentiment Analysis of Audiences on Twitter: Who Is the Positive or Negative Audience of Popular Twitterers?”, In: Lee G., Howard D., Ślęzak D. (eds) Convergence and Hybrid Information Technology. ICHIT 2011. Lecture Notes in Computer Science, vol. 6935. Springer, Berlin, Heidelberg, 2011.
[5] A. C. E. S. Lima and L. N. de Castro, "Automatic sentiment analysis of Twitter messages," 2012 Fourth International Conference on Computational Aspects of Social Networks (CASoN), Sao Carlos, Brazil, pp. 52-57, 2012, doi: 10.1109/CASoN.2012.6412377.

[6] F. Neri, C. Aliprandi, F. Capeci, M. Cuadros and T. By, "Sentiment Analysis on Social Media," 2012 IEEE/ACM International Conference on Advances in Social Networks Analysis and Mining, Istanbul, Turkey, pp. 919-926, 2012, doi: 10.1109/ASONAM.2012.164.

[7] H. Kang, S. J. Yoo, D. Han, "Senti-lexicon and improved Naïve Bayes algorithms for sentiment analysis of restaurant reviews", Expert Systems with Applications, vol. 39(5), pp. 6000-6010, 2012, ISSN 0957-4174, https://doi.org/10.1016/j.eswa.2011.11.107.

[8] M. Ghiassi, J. Skinner, D. Zimbra, "Twitter brand sentiment analysis: A hybrid system using n-gram analysis and dynamic artificial neural network”, in Expert System with Applications , ScienceDirect, vol. 30(16), pp. 6266-6282, Nov 2013.

[9] A. Hassan, A. Abbasi, Daniel Zeng, "Twitter Sentiment Analysis: A Bootstrap Ensemble Framework”, Social Computing (SocialCom), 2013 International Conference, IEEE, INSPEC Accession Number 14024707, PP 357 - 364, 8-14 Sept. 2013.

[10] E. Haddia, X. Liua, Y. Shib, "The Role of Text Pre-processing in Sentiment Analysis" , in the International Conference on Information Technology and Quantitative Management, Elsevier, Procedia Computer Science, Dec 2013.

[11] G. Patil, V. Galande, V. Kekan, K. Dange, "Sentiment Analysis Using Support Vector Machine”, International Journal of Innovative Research in Computer and Communication Engineering, vol. 2, Issue 1, pp. 4249, January 2014.

[12] I. Dilrukshi, K. de Zoysa, "A Feature Selection Method for Twitter News Classification”, in International Journal of Machine Learning and Computing, vol. 4, Issue. 4, August 2014, DOI: 10.7763/IJMLC.2014.V4.438, pp 365-370.

[13] BAC Le, and H. Nguyen, "Twitter Sentiment Analysis Using Machine Learning Techniques", Advanced Computational Methods for Knowledge Engineering, Advances in Intelligent Systems and Computing 358, DOI: 10.1007/978-3-319-17996-4_25, Springer International Publishing Switzerland, pp. 279-289, 2015.

[14] B. S. Dattu, Prof.Deipali V. Gore, "A Survey on Sentiment Analysis on Twitter Data Using Different Techniques”, (IJCSIT) International Journal of Computer Science and Information Technologies, vol. 6 (6), pp 5358 -5362, 2015.

[15] O. Kolchyna, Th'arsis T. P. Souza, Philip C. Treleaven and Tomaso Aste, "Twitter Sentiment Analysis: Lexicon Method, Machine Learning Method and Their Combination”, Cornell University Library, 18 Sep 2015, arXiv :1507.00955.

[16] J. Prusa, Tahhi M. Khoshgoftaar, David J. Dittman, "Using Ensemble Learners to Improve Classifier Performance on Tweet Sentiment Data", Information Reuse and Integration (IRI), IEEE International Conference, pp. 252-257, 13-15 Aug. 2015, INSPEC Accession Number: 15556647.

[17] K. L. Devi, P. Subathra, P. N. Kumar, "Tweet Sentiment Classification Using an Ensemble of Machine Learning Supervised Classifiers Employing Statistical Feature Selection Methods", Proceedings of the Fifth International Conference on "Fuzzy and Neuro Computing (FANCCO - 2015)”, vol. 415, pp. 1-13, Nov 2015.

[18] Y. Wan and Q. Gao, “An Ensemble Sentiment Classification System of Twitter Data for Airline Services Analysis", in 2015 IEEE International Conference on Data Mining Workshop (ICDMW), Atlantic City, NJ, pp. 1318-1325, 2015.

[19] Joseph D. Prusa, Taghi M. Khoshgoftaar, David J. Dittman, "Impact of Feature Selection Techniques for Tweet Sentiment Classification", Proceedings of the Twenty-Eighth International Florida Artificial Intelligence Research Society Conference, pp. 299-304, 2015.

[20] R. Mansour, M. F. A. Hady, E. Hosam, H. Amr,, A. Ashour, "Feature Selection for Twitter Sentiment Analysis: An Experimental Study", International Conference on Intelligent Text Processing and Computational Linguistics, Springer, pp. 92-103, 2015.

[21] O. Abdelwahab, M. Bahgat, C. J. Lowrance and A. Elmaghraby, "Effect of training set size on SVM and Naive Bayes for Twitter sentiment analysis," 2015 IEEE International Symposium on Signal Processing 
and Information Technology (ISSPIT), Abu Dhabi, United Arab Emirates, pp. 46-51, 2015, doi: 10.1109/ISSPIT.2015.7394379.

[22] S. Akter and M. T. Aziz, "Sentiment analysis on Facebook group using lexicon based approach", 2016 3rd International Conference on Electrical Engineering and Information Communication Technology (ICEEICT), Dhaka, pp. 1-4, 2016, doi: 10.1109/CEEICT.2016.7873080.

[23] M. Bouazizi, T. O. Ohtsuki, "A pattern-based approach for sarcasm detection on twitter”, IEEE Access 4, pp. 5477-5488, 2016.

[24] P. Grandin, J. M. Adan, "Piegas: A systems for sentiment analysis of tweets in Portuguese”, IEEE Latin America Transactions, vol. 14(7), pp. 3467-3473, 2016.

[25] Nádia Félix Felipe da Silva, Luiz F.S. Coletta, Eduardo R. Hruschka, Estevam R. Hruschka, "Using unsupervised information to improve semisupervised tweet sentiment classification”, Elsevier journal of Information Sciences, vol. 355-356, pp. 348-365, 10 August 2016.

[26] A. Tripathy, Ankit Agrawal, Santanu Kumar Rath, "Classification of sentiment reviews using n-gram machine learning approach”, in Expert System With Applications, ELSEVIER, pp. 117-126, 2016.

[27] A. Krouska, C. Troussas, M. Virvou, "The effect of preprocessing techniques on Twitter sentiment analysis”, ResearchGate Conference, July 2016, DOI: 10.1109/IISA.2016.7785373.

[28] A. Kashif, H. Dong, A. Bouguettaya, A. Erradi, R. Hadjidj, "Sentiment Analysis as a Service: A Social Media Based Sentiment Analysis Framework", in IEEE International Conference on Web Services (ICWS), Honolulu, HI, USA: IEEE,2017.

[29] A. U. Hassan, J. Hussain, M. Hussain, M. Sadiq S. Lee, "Sentiment analysis of social networking sites (SNS) data using machine learning approach for the measurement of depression", 2017 International Conference on Information and Communication Technology Convergence (ICTC), Jeju, pp. 138-140, 2017, doi: 10.1109/ICTC.2017.8190959.

[30] M. R. Huq, Ahmad Ali, Anika Rahman, "Sentiment Analysis on Twitter Data using KNN and SVM", In (IJACSA) International Journal of Advanced Computer Science and applications, vol. 8, Issue. 6, pp. 1925, 2017.

[31] M. Ahmad, Shabib Aftab, Iftikhar Ali, "Sentiment Analysis of Tweets using SVM", International Journal of Computer Applications (0975 8887), vol. 177 , Issue 5, pp. 25-29, Nov 2017.

[32] J. Brandon, J. Deng, "Sentiment Analysis of Tweets for the 2016 US Presidential Election”, in IEEE MIT Undergraduate Research Technology Conference (URTC), Cambridge, MA, USA: IEEE, 2017.

[33] R. Wijayanti, A. Arisal, "Ensemble approach for sentiment polarity analysis in user-generated Indonesian text”, in 2017 International Conference on Computer, Control, Informatics and its Applications (IC3INA), Jakarta, pp. 158-163, 2017.

[34] Z. Jianqiang and G. Xiaolin, "Comparison Research on Text Preprocessing Methods on Twitter Sentiment Analysis”, IEEE Access, Feb 2017.

[35] M. A. Rahman, V. Mezhuyev, M. Z. A. Bhuiyan, S. N. Sadat, S. A. B. Zakaria, N. Refat, "Reliable decision making of accepting friend request on online social networks”, IEEE Access 6, 9484-9491, 2018.

[36] Z. Jianqiang, G. Xiaolin, Z. Xuejun, "Deep convolution neural networks for twitter sentiment analysis”, IEEE Access 6, 23253-23260, 2018.

[37] K. Tago, Q. Jin, "Influence analysis of emotional behaviors and user relationships based on twitter data", Tsinghua Science and Technology vol. 23(1), pp. 104-113, 2018.

[38] I. Victoria, M. Sharmina, K. Malik, R. Batista-Navarro, "Analyzing Sentiments Expressed on Twitter by UK Energy Company Consumers", in Fifth International Conference on Social Networks Analysis, Management and Security (SNAMS): IEEE, pp. 95- 98, 2018.

[39] C. Troussas, A. Krouska and M. Virvou, "Evaluation of ensemble-based sentiment classifiers for Twitter data, in 7th International Conference on Information”, Intelligence, Systems \& Applications (IISA), Chalkidiki, pp. 1-6, 2016.
[40] M. M. Fouad, T. F. Gharib, A. S. Mashat, "Ecient Twitter Sentiment Analysis System with Feature Selection and Classifier Ensemble”, in International conference on Advanced Machine Learning and Applications, vol. 723, pp. 517-527, Jan 2018.

[41] Y. Emre Isik, Y. Görmez, O. Kaynar, Z. Aydin, "NSEM: Novel Stacked Ensemble Method for Sentiment Analysis", 2018 International Conference on Artificial Intelligence and Data Processing (IDAP), Malatya, Turkey, pp. 1-4, 2018.

[42] F. T. Giuntini, et al., "How Do I Feel? Identifying Emotional Expressions on Facebook Reactions Using Clustering Mechanism", in IEEE Access, vol. 7, pp. 53909-53921, 2019, doi: 10.1109/ACCESS.2019.2913136.

[43] S. E. Saad and J. Yang, "Twitter Sentiment Analysis Based on Ordinal Regression", in IEEE Access, vol. 7, pp. 163677-163685, 2019, doi: 10.1109/ACCESS.2019.2952127.

[44] S. Vashishtha, S. Susan, "Fuzzy rule based unsupervised sentiment analysis from social media posts", Expert Systems with Applications, vol. 138, 2019, 112834, ISSN 0957-4174.

[45] K. Elshakankery, M. F. Ahmed, "HILATSA: A hybrid Incremental learning approach for Arabic 'tweets sentiment analysis", Egyptian Informatics Journal, vol. 20, Issue 3, 2019, pp. 163-171, ISSN 11108665, https://doi.org/10.1016/j.eij.2019.03.002.

[46] Martin-Domingo, Luis, Juan Carlos Martin, and Glen Mandsberg, "Social Media as a Resource for Sentiment Analysis of Airport Service Quality (ASQ).”, Journal of Air Transport Management, 2019.

[47] M. Naz ,K. Zafar, A. Khan, "Ensemble Based Classification of Sentiments Using Forest Optimization Algorithm”, vol. 4, no. 2, pp. 113, May 2019. https://doi.org/10.3390/data4020076.

[48] J. J. Bird, A. Ekárt, C. D. Buckingham, D. R. Faria, "High Resolution Sentiment Analysis by Ensemble Classification”, In: Arai K., Bhatia R., Kapoor S. (eds) Intelligent Computing. CompCom 2019. Advances in Intelligent Systems and Computing, Springer, Cham, vol. 997, June 2019.

[49] M. Khader, A. Awajan, and G. Al-Naymat, "The Impact of Natural Language Preprocessing on Big Data Sentiment Analysis”, International Arab Journal of Information Technology, vol. 16, pp. 506-513, 2019.

[50] R. Ahujaa, A. Chuga, S. Kohlia, S. Guptaa, and P. Ahujaa, "The Impact of Features Extraction on the Sentiment Analysis", International Conference on Pervasive Computing Advances and Applications PerCAA 2019, Procedia Computer Science, vol. 152, pp. 341-348, 2019.

[51] M. bibi, M. S. A. Nadeem, I. H. khan, S. Shim, I. R. Khan, U. Naqvi1 and W. Aziz, "Class Association And Attribute Relevancy Based Imputation Algorithm To Reduce Twitter Data For Optimal Sentiment Analysis”, Oct 2019, pp. 1365535- 1365544, vol. 7.

[52] M. Bibi, W. Aziz, M. Almaraashi, I. H. Khan, M. S. A. Nadeem and N. Habib, "A Cooperative Binary-Clustering Framework Based on Majority Voting for Twitter Sentiment Analysis," in IEEE Access, vol. 8, pp. 68580-68592, 2020, doi: 10.1109/ACCESS.2020.2983859.

[53] Z. Kermani, F., Sadeghi, F. \& Eslami, E., "Solving the twitter sentiment analysis problem based on a machine learning-based approach.”, Evol. Intel. 13, pp. 381-398, 2020. https://doi.org/10.1007/s12065-019-00301$\mathrm{x}$.

[54] Esraa A. Afify, Ahmed Sharaf Eldin and Ayman E. Khedr, "Facebook Profile Credibility Detection using Machine and Deep Learning Techniques based on User's Sentiment Response on Status Message”, International Journal of Advanced Computer Science and Applications(IJACSA), vol. 11(12), 2020.

[55] S.R. George, P. Sujith Kumar, S.K. George, "Conceptual Framework Model for Opinion Mining for Brands in Facebook Engagements Using Machine Learning Tools.”, In: Fong S., Dey N., Joshi A. (eds) ICT Analysis and Applications. Lecture Notes in Networks and Systems, vol. 154. Springer, Singapore, 2021. 